\title{
Themes of agency and communion and rehabilitation from substance misuse
}

Authors: David Rowlands, PhD

\author{
Donna Youngs, $\mathrm{PhD}$ \\ David Canter, PhD
}

Corresponding Author: David Rowlands

Centre for Investigative Psychology

Ramsden Building

The University of Huddersfield

Queensgate

Huddersfield, UNITED KINGDOM

HD1 3DH

Corresponding author email: david.rowlands@hud.ac.uk 


\begin{abstract}
Background: Current models of identity transformation in substance misuse recovery emphasise either communal or agentic growth processes. Building on life narrative studies of addicted males, the present study proposes that agency and communion themes distinguish the narrative identities of rehabilitated substance users from active users.

Method: The 'Life as a Film' (LAAF) task was used to record narratives in an opportunity sample of 32 participants ( 23 males, 9 females) with ongoing or substance misuse history. Transcripts were coded for agency and communion, and external measures of rehabilitation were assessed using a recovery inventory.

Results: Four types of narrative were revealed, according to the presence or absence of agency and communion themes in LAAF accounts. Analysis determined a significant correlation between descriptions of agency and communion and rehabilitation outcomes $(0.91-\mathrm{p}<0.01)$, showing that both identity themes are important to recovery. Participants illustrating either theme showed moderate outcomes and those depicting neither theme showed poor outcomes. Case studies were used to illustrate the instrumentality of agentic and communal growth to behavioural change.

Conclusions: The LAAF method demonstrated value in a narrative approach for expanding current perspectives, indicating that both agency and communion shape identity transformation in recovery from substance misuse. These findings highlight unique intervention needs corresponding with presenting narrative identity.
\end{abstract}

Keywords: Substance Misuse, Narrative, Identity, Recovery, Agency, Communion 


\section{Introduction}

\subsection{Identity transformation}

It was Biernacki (1986) who first approached substance misuse from the perspective of identity, arguing that in chronic drug misuse an 'addict identity' predominates and that recovery requires the rise of compelling alternative self-concepts. Correspondingly, McIntosh and McKeganey (2002) showed that more meaningful identities were constructed in 71 recovering heroin users, and Young (2011) that resolution of identity dialectics was a contingency for rehabilitation from alcoholism, indicating that addiction should be approached as a disorder of identity.

Consolidating the role of identity in rehabilitation, Dingle et al. (2015) revealed that the manifestation of a recovery identity preceded reductions in substance use, highlighting the instrumentality of identity changes to behavioural outcomes (Dingle et al., 2015). This latter research refutes the argument of attribution theorists that self-concepts among substance users and ex-users are constructed ad hoc to preserve the status quo (Newman \& Davies, 2007).

\subsection{Social identity}

Revealing the dynamics of identity transformation is key to our understanding rehabilitative processes. Repeated studies highlight the centrality of support networks in fostering identity change (Litt et al., 2009; Longabaugh et al., 2010; Jetten et al., 2014), leading prominent theorists to adopt social identity perspectives, proposing that rehabilitation from substance misuse is achieved through identification with recovery communities to assume the collective recovery identity (Buckingham, Frings \& Albery, 2013; Frings \& Albery, 2015; Best, Haslam, Haslam \& Jetten et al., 2016). A study of 537 recovering substance users supports this 
interpretation, correlating the emergence of a recovery identity with engagement in 12-Step recovery networks (Bathish et al., 2017).

Social identity models fit neatly with the 12-Step paradigm, where ex-substance users provide a collective with which to identify and reconfigure one's identity (Thune, 1977; Denzin, 1987; Cain, 1991). However, emphasis on social identity may obstruct potential for self-determinism. On this point, Levi (2016) argues that fellowship organisations, far from inhibiting self-agency, foster empowerment through communal membership, while others counter that addiction is a disorder of choice which many people resolve without recourse to recovery groups (Heyman, 2009; Lewis, 2017).

\subsection{Narrative identity}

Dunlop and Tracy (2013) revealed the importance of certain self attributes to recovery, finding that alcoholics who described redemptive sequences following their last drink were more likely to remain abstinent at follow up. The research illustrates how attributing redemptive agency to personal narratives facilitated rehabilitation. Accordingly, Stone (2016) demonstrated how reframing stories with a redemptive focus gave substance users agency to pursue prosocial goals. Related studies in psychotherapy elucidate the instrumentality of self-agentic growth in fostering positive change (Adler, 2012).

Shedding light on these disparate perspectives, Hanninen and Koski-Jannes (1999) revealed different stories that ex-substance users adopt to facilitate identity change and rehabilitation. One type of narrative cited recovery communities as central, while another interpreted agentic growth as key. A third story described a combination of processes, where insight to personal vulnerabilities fostered better relationships. The study highlights the value of applying a narrative perspective in articulating different paths to recovery. 
Reflecting on clinical cases, Weegmann (2010) relates that self-directive and communal dynamics are important to recovery, arguing that research needs to examine both elements to advance pragmatic models. This corresponds with Chen's (2018) contention that both personal and relational growth are important in stimulating positive change. Consistent with this notion, a study of recovering heroin users showed that personal constructs of self-reliance and connecting with others were central to identity changes in rehabilitation $(\mathrm{Ng}, 2002)$.

\subsection{Agency and communion}

Building on Bakan's (1966) idea that agency and communion provide the underpinning dimensions by which human behaviour is shaped, McAdams developed a life story theory of identity (McAdams et al. 1996; McAdams, 1997; McAdams, 2011). Influenced by this work, Singer (1997) describes life stories of chronically addicted men, highlighting agency and communion deficits in the construction of narrative identities that served to maintain substance misuse. Singer (2001) repeated his observations with analysis of a chronic heroin user, explaining how the escape mechanism afforded through substance use compromised central identity imperatives which made recovery untenable.

In considering the shaping influence of agency and communion deficits, Singer's case studies provide an important platform for further research. To develop his arguments, the task of subsequent studies lies with a comparison of addiction narratives and those of rehabilitated substance users. In this way, theme patterns supportive of either behaviour pattern can be revealed, and intervention focus points more clearly identified.

\subsection{Prohibited lives}


In research with criminals, Canter and Youngs (2015) found that the life story approach adopted by McAdams (1997) produced limited narrative responses, while inviting participants to narrate their 'life as a film' elicited psychological rich accounts. The authors argued that this proclivity related to the suitability of a projective device for communicating less well articulated and prohibited lives.

Data collection issues observed with offenders are equally relevant to substance misuse populations, where early victimisation (Oshri et al., 2017; Howard et al., 2017), escapist protocols (Larsson et al., 2013), and social stigma (Young, 2011) create barriers to communication, and typically the cohort demonstrates greater enthusiasm for creative tasks (Moore, 1983; Johnson, 1990; McGranahan \& Lynskey, 2018).

The creative facility of the 'Life as a Film' (LAAF) shares commonality with projective tasks, such as the TAT (Murray, 1938), where vague templates prompt personally relevant storytelling (Rapaport, 1942; Cramer, 1999), while overcoming conscious resistance presented with stock biographical recall (Lindzey, 1952; Bamberg, 2011; Youngs et al., 2016). However, on a point of general parity, McAdams et al. (1996) showed a strong correlation between agency and communion in life narratives and power and intimacy motivation revealed through projective tasks.

Another benefit of the LAAF approach over more protracted life story interviews is its elicitation of a distilled, essential narratives, synopsizing key themes in an active unfolding story (Youngs \& Canter, 2015). Advantages of the LAAF have been corroborated by subsequent studies (Youngs et al., 2016; Kang, Kruttschnitt, \& Goodman, 2017; Tkazky, 2018), including research by the present authors illustrating a strong suitability for substance users (Rowlands, Youngs \& Canter, 2019). 


\subsection{Aims}

The study aims to expand on Singer's $(1997,2001)$ work in sampling a broader population composed of males and females both active in and rehabilitated from substance misuse. This addresses current emphases on recovering populations and will enable us to examine how differences in themes of agency and communion relate to active substance use and recovery.

Exploring the thesis of twin processes re-writing narrative identity towards recovery addresses personal and relational growth dynamics, developing current social identity models. The work is important in promoting psychosocial theories of behaviour that articulate agentic and communal forces in the context of lived experiences. This has value in translating presenting identity into treatment interventions.

Following these objectives, it was hypothesised that participants could be differentiated according to the presence in their LAAF narratives of agency and communion themes, and that cumulative presentation of these themes relates to better rehabilitation outcomes.

\section{Method}

\subsection{Materials}

Recognising data elicitation advantages, the LAAF was used to collect personal narratives. A 12-item Recovery Inventory (RI) (Appendix 1) was designed to compare narrative accounts with rehabilitation outcomes. The inventory draws on recognised recovery indicators, following Groshokova et al.’s (2013) approach, expanding standard abstinence reports to assess other salient issues (Deegan, 1988; Valentine, 2011), including desistance from offending (Sampson \& Laub, 1990), employment (McIntosh, Bloor \& Robertson, 2008), social networks (Bathish et al. 2017), personal wellbeing (Best et al., 2012), emotional support (Leamy et al., 
2011), and self-identity (Dingle et al., 2015), embodying the shift towards psychosocial approaches to intervention and rehabilitation (Turton, 2014).

The scale marks ' 1 ' for presence and ' 0 ' for absence of an item. Cronbach's reliability test produced an Alpha value of 0.91, confirming a high level of internal consistency supportive of a quantitative interpretation (Skinner \& Allen 1982).

\subsection{Participants}

An opportunity sample was gathered of 32 participants, composed of 23 males and 9 females. Inclusion criteria was self-report of current or historical problematic substance use. Subjective report recognises the experience of individuals as key in presenting psychological issues (Kelly, 1955; Deegan, 1988; Singer, 2001).

Recruitment was initiated by the author's links to local Alcoholics Anonymous and Narcotics Anonymous fellowships (AA/NA). This facilitated referral to other community service users, as well as needle exchange users, active substance users not engaged in treatment, and rehabilitated substance users in the wider community.

The largest ethnic group was Caucasians $(\mathrm{n}=31)$ and one Asian participant, with an age range of 29-60 and a mean age of 39.85. Twelve participants reported abstinence at the time of study, 9 of which reporting abstinence for more than 12 months. Twenty participants reported active substance use, though 8 participants stated their current use was non-problematic.

The sample recruited a diverse range of substance issues, representing alcohol, opiate, stimulant and benzodiazepine misuse, though most participants reported a history of polysubstance use $(n=21)$, combined heroin and crack cocaine use $(n=9)$ being the most prevalent. 
Participants in recovery had rehabilitated by various means, including their own efforts, access to community treatment services, recovery communities, and/or inpatient rehabilitation facilities.

\subsection{Procedure}

Participants were given an information sheet detailing the topic of research. After agreeing to participate, a confidentiality document was signed. Interviews were conducted via videocall and recorded. Videocall was preferred, since it offered convenience and the comfort of a familiar location. The LAAF was completed, with participants being given a series of prompts from which to construct responses in sequence (see Table 1).

\begin{tabular}{|l|}
\hline \\
$\qquad$ 'Life as a Film' procedure - Sequence of Prompts \\
\hline If your life were to be made into a film, what type of film would it be? \\
\hline What would happen? \\
\hline Who would the main characters be? \\
\hline What would be the main events that might happen in the film? \\
\hline How do you think it might end? \\
\hline What happens in the most exciting scene in the film? \\
\hline Where is it? \\
\hline What is going on? \\
\hline Who else is there? \\
\hline What are they doing? \\
\hline How are you acting? \\
\hline How do you feel? \\
\hline When does the film start? \\
\hline What is going on? \\
\hline What are you like then? \\
\hline What sort of person are you? \\
\hline Who you have good feelings about and why? \\
\hline Who do you have bad feelings about and why? \\
\hline What do other people think about you? \\
\hline What mistakes do you make? \\
\hline How do you change during the film? \\
\hline
\end{tabular}

Table 1, showing the sequence of LAAF prompts 
The RI was then completed, where participants were asked to self-report on each of the list of indicators, and a debrief provided, with opportunity for questions, and signposting to local support services given.

Recordings were transcribed and then deleted. The transcribed material was anonymised (with participants being assigned a personal number) and kept in a secure, locked location.

Though constructing film narratives may have anchored thought processes, since the RI focuses on explicit behaviours, such as abstinence, employment, desistance from crime, and other activities, it was considered unlikely to significantly confound data, while commencing with recall of these more objective indicators was thought likely to influence narrative constructs (Wang \& Ross, 2005).

\subsection{Coding of themes}

Following reliable coding protocols (McAdams et al., 1996; Canter \& Youngs, 2015), LAAF transcripts were coded for themes of agency and communion:

Agency

Effectiveness - The protagonist develops skills, experiences achievement, gains rewards.

Empowerment - The protagonist is enlarged, enhanced, empowered or ennobled.

Self-Mastery - The protagonist strives to successfully master, control, and perfect the self.

\section{Communion}

Love/Friendship - The protagonist experiences an enhancement of love or friendship toward another person. 
Caring - The individual reports that he or she provides care, assistance, nurturance, help, aid, support, or therapy for another.

Unity - The theme of Unity/Togetherness captures the communal idea of being part of a larger community.

As with previous narrative research, binary scoring coded presence $(1)$ or absence $(0)$ of each element (Canter \& Youngs, 2015). This meant that a score of between 0 and 3 was possible for each theme. A cumulative score of $2 / 3$ was taken to reflect a 'narrative theme'. For example, scoring on the elements empowerment and effectiveness denoted high agency, low communion, whereas scoring on empowerment and effectiveness as well as love and caring denoted high agency, high communion. In contrast, describing less than two elements for either theme reflected low agency, low communion.

Cronbach's reliability test produced an Alpha value of 0.77 for communion elements and 0.82 for agency elements, showing a high level of internal consistency supportive of quantitative interpretation (Skinner \& Allen 1982).

Transcripts were coded by two independent coders. Coders were $\mathrm{PhD}$ students practised in thematic coding of narrative material. Cohen's kappa was used to assess agreement between coders on a sample of 15 transcripts, producing a coefficient of 0.72 and a good level of agreement (Altman, 1991). 


\section{Results}

\subsection{Thematic groups}

The sample was ordered into groups according to theme combinations (see Appendix 2). Table 2 shows group differences in recovery outcomes, as follows.

Group 1: low agency, low communion (LALC) - low recovery scores.

Group 2: low agency, high communion (LAHC) - moderate recovery scores.

Group 3: high agency, low communion (HALC) - moderate recovery scores.

Group 4: high agency, high communion (HAHC) - high recovery scores.

\begin{tabular}{|l|c|c|c|c|}
\hline Narrative Group & No. of cases & No. Male & No. Female & Median RI score \\
\hline LALC & 7 & 4 & 3 & 2 \\
\hline LAHC & 4 & 3 & 1 & 5.5 \\
\hline HALC & 10 & 6 & 4 & 6 \\
\hline HAHC & 11 & 8 & 4 & 12 \\
\hline
\end{tabular}

Table 2: showing descriptive data between groups

\subsection{Theme profiles and recovery outcomes}

To examine the relationship between recovery outcomes and themes in LAAF narratives, correlational analysis was run. The one tailed hypothesis produced a Spearman's correlation coefficient of $0.91(\mathrm{p}<0.01)$, revealing a high positive linear correlation between the presence of agency and communion themes in LAAF accounts and scores on the RI.

Figure 1. displays three regions, which can be interpreted as follows: (1) participants depicting both agency and communion themes show robust rehabilitation outcomes (2) participants 
depicting either agency or communion show moderate rehabilitation outcomes (3) participants depicting neither agency nor communion show poor rehabilitation outcomes.

These results suggest that the best recovery outcomes reflect a high agency and communion narrative identity, supporting a twin processes model of substance misuse recovery. The centre ground observed with moderate recovery scores and agency or communion indicates that models focused on either agentic or communal identity limit our perspective.

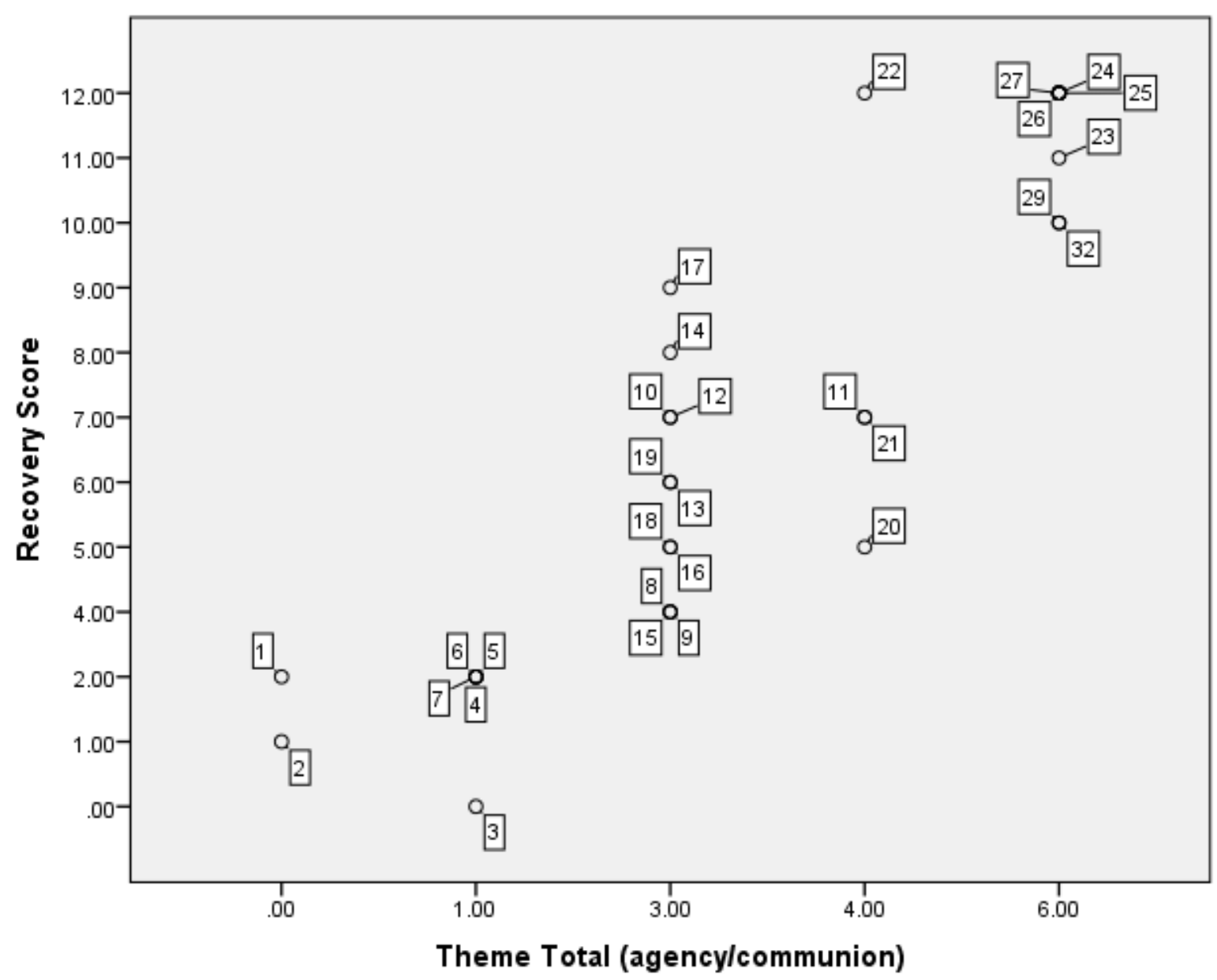

Figure 1. Scatterplot showing the relationship between agency and communion themes in $L A A F$ narratives and recovery scores 


\subsection{Case Studies}

Correlation data, while indicative, does not illustrate instrumentality; however, case studies help to elucidate developmental processes. In the following example, a trajectory from a low agency and communion identity with a lifestyle of drug misuse, to a high agency and communion identity with recovery from substance misuse is depicted:

Case 31: Then at 15 being relentlessly bullied because of being the poor kid.... then meeting a terribly controlling man who beat her when he couldn't get a fix, giving her pills to 'help take the pain away'... in the end beating her so bad because she would not shoplift for him she ended up in hospital...dependant on temazepam. This is where she met a policeman who would change her life forever. Then at 21 joining the Army. Gaining true friends and acceptance. Gaining more life experience and pride than most people could ever wish for. Serving in Afghanistan and Iraq, but mainly having the ability to engage and talk to anyone.... Definitely a happy ending. The girl would ride off into the sunset on a horse with her arms around her prince charming...

The LAAF charts a perception of powerlessness and isolation in drug dependency progressing to empowerment and unity in a film of struggle to triumph. It vividly illustrates the redemption theme shown by Dunlop and Tracy (2013) and Stone (2016) research, while expanding the concept to incorporate both agentic and communal growth processes.

The following LAAF, similarly, recognises a growing sense of personal agency and how this was important to rehabilitation:

Case 25: A character who always had mates, but the wrong mates.... trying to escape the nonsense with drugs. It'd show me failing over again and people giving up on me, but how I kept going and gradually got the guts and will to crack on..... By the end, you see me happy, 
just passed my driving test and got a job. Then it'd end with a mad party round my gaff. No drugs, ha-ha.

The same participant illustrates how communion is also central in conceptualising his recovery:

Case 25: ...But you'll see me contemplating using and the screen will split to ten phone calls to mates telling me 'don't do it' and me just falling asleep in front of the TV with my bird instead.

The above examples depict how concepts of agentic and communal growth may facilitate recovery, while the case below highlights the reverse storyline, where a low agency and communion self-attribution reinforces substance misuse:

Case 2: I just fall further into the trap. Just a number of predicaments and not being able to grasp why...._t would be a film about someone who started off having a laugh with his mates and trying things out, but then falling into a predicament and getting confused... You know, I had a lot of big ideas growing up and then suddenly they were all gone and I was on my own, drinking.

This narrative is typical of individuals still active in addiction. Other participants described narratives showcasing agency or communion. The passage below illustrates a high agency interpretation of positive change:

Case 21: Then there's a powerful scene where all the shit from the last 10 years rushes into his head and he breaks down in front of the mirror, and then smashes it, smashing his tears to pieces and just gets strong from there. Err, dunno, just uses that desperation to power him forward.... Stops smashing drugs. Get control of his life. You see him looking smart preening in front of the mirror the next day, ha-ha. New mirror. Final scene shows him standing proud in a house he's just done up 
Corresponding with other high agency, low communion identities, though citing personal agency, this individual continues to use substances, falling short of more robust recovery profiles demonstrated by high agency and communion narrative identities.

Conversely, the LAAF below emphasises the instrumentality of communal growth in breaking free from drug dependency, while making a recognition of personal powerlessness:

Case 9: The film would just freeze with a picture of him in a puddle of piss, helpless and a total stranger helping him up. It's the turning point. The man realises he's helpless on his own so reaches out for help.... like this man who help him build back his life.... In a later scene he is there joining hands with other ex-addicts and feeling grateful.

In common with others describing high communion, low agency narratives, this participant struggles to maintain abstinence, equally failing the comprehensive recovery demonstrated by high agency and communion narrative identities.

The case studies suggest that individuals active in addiction identify themselves by low agency and communion narratives, while rehabilitated substance users conceive high agency and communion narratives, reflecting a transformed identity, and illustrate how agency and communion growth themes support recovery. Narratives emphasising either theme represent an intermediate position on the substance misuse-recovery trajectory, indicating some control over substance use, often falling short of full rehabilitation.

\section{Discussion}

The results showed that participants' LAAF narratives could be meaningfully differentiated according to combinations of agency and communion, revealing four narrative identities 
among the sample that related to different rehabilitation outcomes. Correlational analysis revealed a strong relationship between the presence of agency and communion in film descriptions and recovery outcomes, while the absence of agency and communion in LAAF accounts related to non-recovery. A highly agentic or communal narrative identity was associated with intermediate rehabilitation outcomes.

Case study examples indicated identity growth themes nourishing rehabilitation, following other researchers' arguments that personal narratives are instrumental to behaviour (Bruner, 1987; Crossley, 2000; Presser, 2009; Youngs \& Canter, 2012; Singer et al., 2013), and were useful in depicting four different presentations of narrative identity among the participants.

These results suggest that identity transformation in full recovery relates to an evaluation of self-identity as both agentic and communal, and that the presence of either but not both themes indicates an intermediate position on the substance misuse-recovery trajectory. In this, key distinctions are revealed between the narrative identities of active users, recovering users and rehabilitated users, providing a model of identity change and recovery expanding the purview of contemporary theories that emphasise either communal (e.g. Best et al., 2016) or agentic (e.g. Stone, 2016) processes.

Distinction in the way active substance users and rehabilitated users construct their life narratives highlights a process of reconstructed identity facilitating recovery (McDonnell \& Snoek, 2018). The findings build on Singer's (1997, 2001) studies with addicted males, elucidating how reconstructed stories attribute agentic and communal growth themes, fusing purpose with unity to propel individuals from identities sustaining substance use to rehabilitation.

Developing Weegmann (2010) and Chen's (2018) ideas, the analogue of rehabilitation trajectories in narrative identity carries important treatment implications, specifically that narratives devoid of communion require a focus on the value of meaningful relationships and 
social support, and those devoid of agency a focus on recognising personal impediments to competency and change. Where neither theme is present, dual emphasis is necessary.

Corresponding with previous indications (Rowlands et al., 2019), the study supports use of the LAAF for collection of personal narratives in substance misuse samples, participants finding the exercise engaging and reporting psychologically rich material. The brevity of the procedure also provides an advantage for data collection and analysis. Future research should expand the analysis to examine redemption and contamination constructs as mediators of recovery versus non-recovery, following findings that the themes are central to desistance or persistence in offenders (Maruna, 2001).

A strength of the research over previous studies is observed with inclusion of individuals both active in substance use and in recovery, allowing for comparisons of contrasting narratives. Equally, a range of treatment pathways were represented, including 12-Step, community-based treatment and self-help. The latter of which has been missing from the research literature and is especially important in recognising highly agentic recovery pathways.

The small sample size presents a limitation on the generalisability of findings; however, it affords a more in-depth case analysis, in common with other narrative research that has produced important insights which have gone on to be confirmed by larger scale studies (e.g. Singer, 2001). In revealing four distinct narrative groups that correspond with rehabilitation outcomes, the study certainly justifies future research with larger samples.

The inclusion of female participants in the sample expands Singer's (1997) observations in males, and though more males than females took part in the study, the gender disparity corresponds with sex differences in presenting clinical cases (Becker \& Hu, 2008). However, the growing prevalence of 'legal high' use is unrepresented, which reflects demographic limitations. Subsequent studies should recruit from younger age groups to better address these shortcomings (Rychert \& Wilkins, 2018) 
Thematic coding reduces responses to quantifiable items. In this process the nuances of personal stories may be lost whilst scoring pre-conceived content. Efforts were made to eliminate the impact of this by: (1) selecting themes previously shown to be important in identity processes and (2) providing case study examples of the narratives processes being studied.

The RI provided an efficient measurement tool, highlighting key indicators of rehabilitation; however, binary scoring may have missed subtle differences, and perhaps future studies could apply a Likert-type scale to protect against this. Likewise, subsequent research may benefit from additional supportive measures, such as the World Health Organisation Quality of Life Questionnaire (WHOQOL) (WHO, 2004).

As a counterpoint to criticism that the LAAF and RI assess two separate but related self-reports, it should be stressed that the RI focuses on explicit phenomena and indicators used in related research (e.g. Groshokava et al., 2013), the report of which is distinct from intrinsic dynamics revealed through projective tasks (Lindzey, 1952). Rather, correspondence between the two measures attests to the mirror of narrative identity in behaviour (Crossley, 2000).

Potential shortcomings of self-report, such as social desirability and memory deficits, are balanced by the benefits of personal perspective. An additional advantage is observed in circumventing the impact of social desirability with use of the LAAF over standard narrative methods (Youngs et al., 2016). However, to account for confounding influences, future research should enlist supportive measures using other substantive personality scales. 


\section{Conclusions}

The LAAF approach was useful for expanding current models in revealing that active substance misuse relates to a low agency and communion narrative identity, moderate rehabilitation to a high agency or communion narrative identity, and robust rehabilitation to a high agency and communion narrative identity. Illustration of unique narrative presentations at different stages of substance use and rehabilitation carries important implications for treatment interventions.

Findings highlight the value of a narrative approach, indicating that both agency and communion shape identity transformation in recovery from substance misuse, which is written into the new narrative identity.

\section{References}

Adler, J. E. (2012). Living into the story: agency and coherence in a longitudinal study of narrative identity development and mental health over the course of psychotherapy, Journal of Personality and Social Psychology, 102(20): 367-389.

Altman, D. G. (1991). Practical Statistics for Medical Research, Chapman \& Hall, London.

Bakan, D. (1966). The duality of human existence: An essay on psychology and religion. Oxford, Rand McNally.

Bamberg, M. (2011). Who am I? Narration and its contribution to self and identity, Theory and Psychology, 21(1): 3-24.

Bathish, R., Best, D., Savic, M., Beckwith, M., MacKenzie, J., \& Lubman, D. I. (2017). 'Is it me or should my friends take the credit?' The role of social networks and social identity in recovery from addiction, Journal of Applied Social Psychology, 47: 35-46.

Becker, J. B. \& Hu, M. (2018). Sex differences in drug abuse, Frontiers in Neuroendocrinology, 29(10): 36-47.

Best, D. (2012) Addiction Recovery: A Movement for Social Change and Personal Growth in the UK, Pavilion Publishing.

Best, D., Beckwith, M., Haslam, C., Haslam, A., Jetten, J., Mawson, E., \& Lubman, D. I. (2016) Overcoming alcohol and other drug addiction as a process of social identity transition: the social identity model of recovery (SIMOR), Addiction Research \& Theory, 24(2): 111-123. 
Biernacki, P. (1986). Pathways from heroin addiction: recovery without treatment. Temple University Press.

Bruner, J. (1987). Life as narrative, Social Research, 54(1): 11-32.

Buckingham, S., Frings, D., \& Albery, I. (2013). Group membership and social identity in addiction recovery, Psychology of Addictive Behaviors, 27: 1132-1140.

Cain, C. (1991). Personal stories: Identity acquisition and self-understanding in Alcoholics Anonymous, Ethos, 19(2): 210-253.

Canter, D. V. \& Youngs, D. E. (2015). The LAAF procedure for exploring offenders' narratives, The Howard Journal of Criminal Justice, 54(3): 219-236.

Chen, G. (2018). Building Recovery Capital: The Role of "Hitting Bottom" in Desistance and Recovery from Substance Abuse and Crime, Journal of Psychoactive Drugs, 50(5): 420-429.

Cohen, J. (1960). A coefficient of agreement for nominal scales, Educational and Psychological Measurement, 20(1): 37-46.

Cohen, J. (1968). Weighted kappa: Nominal scale agreement with provision for scaled disagreement or partial credit, Psychological Bulletin, 70(4): 213-220.

Cramer, P. (1999). Future directions for the Thematic Apperception Test, Journal of Personality Assessment, 72(1): 74-92.

Crossley, M. L. (2000). Narrative Psychology, Trauma and the Study of Self/Identity, Theory \& Psychology, 10(4): 527-546.

Deegan, P. E. (1988). Recovery: The lived experience of rehabilitation, Psychosocial Rehabilitation Journal, 11: 11-19.

Denzin, N. (1987). The Recovering Alcoholic, Newbury Park, CA.

Dingle, G. A., Stark, C., Cruwys, T., \& Best, D. (2015). Breaking good: Breaking ties with social groups may be good for recovery from substance misuse, The British Journal of Social Psychology, 52(2): 236-254.

Dunlop, W. L. \& Tracy, J. L. (2013). Sobering Stories: Narratives of self-redemption predict behavioural change and improved health among recovering alcoholics, Journal of Personality and Social Psychology, 104(30): 576-590.

Frings, D. \& Albery, I. (2015). The social identity model of cessation maintenance: Formulation and initial evidence, Addictive Behaviors, 44: 35-42.

Groshokova, T., Best, D. \& White, W. L. (2013). The Assessment of Recovery Capital: Properties and psychometrics of a measure of addiction recovery strengths, Drug and Alcohol Review, 32(2): 187-194.

Hanninen, V. \& Koski-Jannes, A. (1999). Narratives of recovery from addictive behaviour, Addiction, 94(12): 1837-1848.

Heyman (2009). Addiction: a disorder of choice. Cambridge, Harvard University Press. 
Howard, R., Karatzias, T., Power, K., \& Mahony, A. (2017). Posttraumatic stress disorder (PTSD) symptoms mediate the relationship between substance misuse and violent offending among female prisoners, Social Psychiatry Psychiatric Epidemiology, 52: 21-25.

Jetten, J., Haslam, C., Haslam, S. A., Dingle, G., \& Jones, J. M. (2014). How groups affect our health and wellbeing: The path from theory to policy, Social Issues and Policy Review, 8(1): 103-130.

Johnson, L. (1990). Creative therapies in treatment of addictions: The art of transforming shame, The Arts in Psychotherapy, 17: 299-308.

Kang, T., Kruttschnitt, C., \& Goodman, P. (2017). Multi-Method Synergy: Using the Life History Calendar and Life as a Film for Retrospective Narratives, The Howard Journal of Crime and Justice, 56(4): 532-553.

Kelly, G. A. (1955). The Psychology of Personal Constructs: Volume 1 and 2. New York, Norton.

Larsson, S., von Braun, T., \& Lilja, J. (2013). A multi-dimensional model for narrative analysis of substance use related dependency, Substance use \& Misuse, 48: 1306-1316.

Leamy, M., Bird, V., Le Boutillier, C., Williams, J., \& Slade, M. (2011). Conceptual framework for the personal recovery in mental health: systematic review and narrative synthesis, The British Journal of Psychiatry, 199: 445-452.

Levi, D. S. (2016). The power of powerlessness, Philosophy Investigations, 39(3): 237-253.

Lewis, M. (2017). Addiction and the Brain: Development, Not Disease, Neuroethics, 10(1): 7-18.

Litt, M. D., Kadden, R. M., Kabela-Cormier, E., Petry, N.M. (2009). Changing network support for drinking: Network Support Project 2-year follow-up, Journal of Consulting Clinical Psychology, 77: 229-242.

Lindzey, G. (1952). Thematic Apperception Test: interpretative assumptions and related empirical evidence. Psychological Bulletin, 49(1): 1-25.

Longabaugh, R., Wirtz, P. W., Zywiak, W. H., \& O’Malley, S. S. (2010). Network support as a prognostic indicator of drinking outcomes: the COMBINE study, Journal of Studies on Alcohol and Drugs, 71(6): 837-846.

McAdams, D. P. (1997). The stories we live by: personal myths and the making of the self, London, Guilford Press.

McAdams, D. P. (2011). Narrative identity. In S. J. Schwartz, K. Luyckx, \& V. L. Vignoles (Eds.), Handbook of identity theory and research (pp. 99-115). New York, Springer Science + Business Media.

McAdams, D.P.; Hoffman, B.J.; Day, R. \& Mansfield, E.D. (1996). Themes of Agency and Communion in significant autobiographical scenes, Journal of Personality, 64(2): 339-377.

McConnell, D. \& Snoek, A. (2018). The Importance of Self-Narration in Recovery from Addiction, Philosophy, Psychiatry \& Psychology, 25(3): 31-44. 
McGranahan, K. \& Lynskey, M. T. (2018). Do creative arts therapies reduce substance misuse: A systematic review, The Arts in Psychotherapy, 57: 50-58.

McIntosh, J., Bloor, M., \& Robertson, M. (2008). Drug treatment and the achievement of paid employment, Addiction Research \& Theory, 16(1): 37-45.

McIntosh, J. \& McKenaney, N. (2002). Beating the Dragon: The Recovery From Dependent Drug Use, London: Prentice Hall.

Maruna, S. (2001). Making Good: How ex-convicts reform and rebuild their lives, Washington DC: American Psychological Association.

Moore, R. W. (1983). Art therapy with substance abusers: A review of the literature, The Arts in Psychotherapy, 10(4): 251-260.

Murray, H. A. (1938). Explorations in personality: a clinical and experimental study of fifty men of college age. Oxford: Oxford University Press.

Newham, R. \& Davies, J. B. (2007). Attributions given by drug users from three different settings, Addiction Research \& Theory, 15(3): 299-308.

Ng, H. (2002). Drug use and self-Organisation: A Personal Construct Study of Religious Conversion in Drug Rehabilitation, Journal of Constructivist Psychology, 15(4): 263-278.

Oshri, A., Carlson, M. W., Kwon, J. A., Zeichner, A. \& Wickrama, K. K. A. S. (2017) Developmental growth trajectories of self-esteem in adolescence: Associations with child neglect and abuse in young adulthood, Journal of Youth and Adolescence, 46: 151-164.

Presser, L. (2009) The Narratives of Offenders, Theoretical Criminology, 13(2): 177-200.

Rapaport, D. (1942). Principles underlying projective techniques, Character \& Personality: A Quarterly for Psychodiagnostic \& Allied Studies, 10: 213-219.

Rowlands, D., Youngs, D., \& Canter, D. (2019). Exploring an agency-communion model of identity transformation in recovery from substance misuse, Journal of Substance Use, 24(3): 265-272.

Rychert, M. \& Wilkins, C. (2018). "A critical analysis of the implementation of a legal regulated market for new psychoactive substances ("legal highs") in New Zealand", International Journal of Drug Policy, 55: 88-94.

Sampson, R. J. \& Laub, J. H. (1990) Crime and Deviance Over the Life Course: The Salience of Adult Social Bonds. American Sociological Review, 55(5): 609-627.

Singer, J. A. (1997). Message in a bottle: stories of men and addiction. New York, Free Press.

Singer, J.A. (2001). Living in the amber cloud: A life story analysis of a heroin addict, Qualitative Psychology, 1: 33-48.

Singer, J.A., Blagov, P., Berry, M., Oost, K.M. (2013). Self-defining memories, scripts, and the life story: narrative identity in personality and psychotherapy, Journal of Personality, 81(6).

Skinner, H. A. \& Allen, B. A. (1982). Differential assessment of alcoholism: Evaluation of the Alcohol Use Inventory, Journal of Studies on Alcohol, 44(5): 852-862.

Stone, R. (2016). Desistance and Identity Repair: Redemption narratives as resistance to stigma, The British Journal of Criminology, 56(5): 956-975. 
Thune, C. E. (1977). Alcoholism and the archetypal past: A phenomenological perspective on Alcoholics Anonymous, Journal of Studies on Alcohol, 38(1): 75-88.

Tkazky, S. (2018). Prisoners' 'Life as a Film'. Doctoral thesis, University of Huddersfield Repository.

Turton, W. (2014). An introduction to psychosocial interventions. In S. Walker (Ed), Psychosocial Interventions in Mental Health Nursing (pp. 5-21). Sage, London.

Valentine, P. (2011). Peer-based recovery support services within a recovery community organization: The CCAR experience. In J.F. Kelly \& W.L. White (Eds.), Addiction recovery management (pp. 259-279). New York, Humana Press.

Wang, Q., \& Ross, M. (2005). What we remember and what we tell: The effects of culture and self-priming on memory representations and narratives. Memory, 13(6): 594-606.

Weegmann, M. (2010). Just a story: narrative approaches to addiction and recovery, Drugs and Alcohol Today, 10.

WHO (2004) The World Health Organisation Quality of Life (WHOQOL) -BREF.

Youngs, D. E. \& Canter, D. V. (2012). Narrative roles in criminal action: an integrative framework for differentiating offenders, Legal \& criminological Psychology, 17(2): 233-249.

Youngs, D. E., Canter, D. V., \& Carthy, N. (2016). The offender's narrative: unresolved dissonance in life as a film (LAAF) responses, Legal \& Criminological Psychology, 21(2): 251-265.

Young, L. B. (2011). Personal Construct Theory and the Transformation of Identity in Alcoholics Anonymous, International Journal of Mental Health and Addiction, Vol.9, 6: 709722. 
